\title{
Gilles de la Tourette Syndrome
}

\author{
O. Suchowersky
}

\begin{abstract}
Gilles de la Tourette syndrome is a neurological disorder characterized by the presence of motor and vocal tics. Other associated features include complex motor and vocal tics, obsessive compulsive behavior and attention-deficit disorder. Although initially thought to be a rare condition, it now appears that the gene for Tourette syndrome may be present in as many as one in a thousand people, and is transmitted as an autosomal dominant trait. However, many individuals carrying the gene may exhibit only minimal symptoms. Neuropathophysiology of Tourette syndrome is unknown but investigations have suggested that the cause may be an abnormality either in the dopaminergic or endorphin receptor system within the basal ganglia. Treatment of Tourette syndrome involves education and counseling of the patient and family. Medications such as neuroleptics, serotonin-reuptake inhibitors, and stimulants are available to treat the manifestations of Tourette syndrome and need to be individualized for each patient.
\end{abstract}

\begin{abstract}
Résumé: Syndrome de Gilles de la Tourette. Le syndrome de Gilles de la Tourette est une affection neurologique caractérisée par la présence de tics moteurs et vacaux. D'autres manifestations y sont associées : des tics moteurs et vocaux complexes, un comportement obsessif compulsif et des troubles de l'attention. Bien qu'on ait longtemps considéré que cette affection était rare, il semble actuellement qu'un individu sur mille serait porteur du gène responsable de la maladie et que ce gène est transmis de façon autosomale dominante. Cependant, plusieurs individus qui sont porteurs du gène peuvent présenter des manifestations très légères. La neurophysiopathologie du syndrome de Gilles de la Tourette est inconnue. Certaines études ont suggéré que la cause peut être une anomalie soit du système des récepteurs dopaminergiques ou du système des récepteurs aux endorphines dans les noyaux lenticulaire, caudé, amygdalien et l'avant-mur. Le traitement du syndrome de Gilles de la Tourette comporte l'éducation et le conseil auprès des patients et de leur famille. Une médication, telle les neuroleptiques, les inhibiteurs de la recaptation de la sérotonine et les stimulants, est disponible pour traiter les manifestations du syndrome de Gilles de la Tourette et doit être individualisée pour chaque patient.
\end{abstract}

Can. J. Neurol. Sci. 1994; 21: 48-52

Gilles de la Tourette syndrome (TS) is a disorder characterized by multiple motor and vocal tics which are waxing and waning in nature. Other abnormalities which may be associated include attention deficit disorder, and obsessive compulsive symptomatology.

The first case of an affected patient was published by Itard in 1825: he described a French noblewoman who exhibited involuntary movements and obscene vocalizations. In 1885, Gilles de la Tourette described his findings on 9 patients identifying clearly the symptom complex of multiple tics, echolalia and coprolalia. Although he felt it was a non-progressive hereditary neurological disorder, neurologists and psychiatrists of the early 20th century believed this to be a rare psychogenic condition causing severe disability. Recent observations have confirmed Gilles de la Tourette's initial impression, and in addition, have shown it to be a relatively common, hereditary disorder with variable manifestations, many cases of which are mild or respond satisfactorily to treatment.

\section{Clinical Manifestations}

\section{Tics}

Motor tics are involuntary, brief jerky movements which may affect any body part. Tics are typically preceded by a feeling of tension buildup, which is then released by the movement. Tics may be suppressed for minutes to hours, depending on the situation, and severity. Typically aggravating factors are anxiety, stress, and fatigue, while alcohol, relaxation or concentration on an enjoyable task may lead to improvement. Interestingly, many patients will have an exacerbation of tics while watching television.

Motor tics can be divided into simple and complex. Simple motor tics involve simple movements, i.e., shoulder shrugging, eyelid blinking, rolling up of eyes, and head nodding. Occasionally, the tics may be slower or more prolonged in duration, akin to dystonic movements. Complex motor tics refer to semi-purposeful movements, i.e., touching oneself, other people or objects, jumping, and skipping. Similarly, vocal tics can be divided into simple (grunting, sniffing, throat clearing, barking) or complex (coprolalia, echolalia, palilalia). ${ }^{2}$

From the Movement Disorders Clinic, Department of Clinical Neurosciences, Faculty of Medicine. University of Calgary. Calgary.

RECEIVED MAY 28, 1993. ACCEPTED IN FINAL FORM SEPTEMBER 13, 1993.

Reprint requests to: O. Suchowersky. MD. FRCPC. FCCMG. Movement Disorders Clinic. Department of Clinical Neurosciences. Faculty of Medicine, University of Calgary, Calgary, Alberta, Canada T2N 4N 
In most patients, tics begin between the ages of 5 and 10 and $96 \%$ of all patients will have symptoms by the age of $11 .{ }^{3}$ Typically the head and neck are the site of initial involvement with eyelid blinking, head jerking, and rolling of the eyes representing the most commonly observed tics. Vocal tics usually follow the onset of the motor tics within several years, but may be the presenting complaint in up to $37 \%$ of patients, ${ }^{4}$ the most frequent one being throat clearing.

Tics will vary in severity, waxing and waning over the course of months. The location of the tics will also vary, affecting one body part for weeks to months, then disappearing, only to reappear in another location or form. Occasionally, tics will become so severe that self-mutilatory behaviour results. Contrary to most movement disorders, tics persist during sleep, and may lead to sleep disturbances.

According to the Diagnostic and Statistical Manual of Mental Disorders III, (1980), in order to make a diagnosis of Tourette's syndrome one has to have the presence of both multiple motor and vocal tics, for longer than 1 year in duration, and beginning prior to 21 years of age. In the past, coprolalia was reported to be present in the majority of patients, but now is known to be an uncommon feature occurring in $10 \%$ or less of all patients. ${ }^{5}$

\section{Obsessive - Compulsive Behaviour}

Obsessions are defined as unwanted intrusive thoughts, and compulsions refer to ritualistic activity designed to produce or prevent a future event. Both are increased in individuals with TS, the reported frequency varying from $45 \%{ }^{6}$ to $63 \% .^{7}$ In some patients, a symptom continuum may exist between complex tics and compulsions.

In several studies, individuals diagnosed with obsessivecompulsive disorder (OCD) have been demonstrated to have a higher than expected frequency of tics. ${ }^{7.8}$ Other studies of relatives of TS patients have demonstrated an increased incidence of OCD in individuals with no tics, particularly in women. ${ }^{9}$ These findings suggest that obsessive - compulsive symptoms are an integral part of Tourette's syndrome, and may occur either in isolation or in combination with tics.

\section{Other Associated Abnormalities}

Although not necessary for the diagnosis, the majority of individuals will exhibit other problems. Up to $62 \%$ of children will have features of attention deficit disorder (ADD) including hyperactivity, decreased concentration, and impulsivity, and up to $26 \%$ will have learning disabilities, most commonly dyslexia. ${ }^{10}$ Symptoms of ADD may predate the onset of tics by up to 2.5 years. ${ }^{\prime}$

Comings and Comings reported an increase in prevalence of other behaviour problems including enuresis, sleep disorders, " phobias and increased anxiety, ${ }^{12}$ depression, ${ }^{13}$ and conduct disorders such as discipline problems, aggressive behaviour, drug and alcohol abuse. ${ }^{14}$ These findings remain controversial as they were based on self-reporting patient questionnaires. Some behaviours, such as depression and anti-social behaviour most likely represent secondary effects of the psychological consequences of dealing with TS. The increase incidence of problems as phobias and perhaps even ADD, have been suggested to be due to ascertainment bias, and/or invalid study design. ${ }^{2.15}$

\section{Neurological Examination and Investigations}

Most patients with TS have a normal neurological examination, outside of the movement disorder. Mild neurological deficits, such as poor motor coordination, reflex asymmetry, pronator drift, and mirror movements may be found in up to $29 \%$ of children.' The significance of these abnormalities is unknown, and they disappear with time. Similarly, non-specific EEG abnormalities can be seen in up to $47 \%$ of patients, ${ }^{3}$ and are more prevalent in children than in adults. No paroxysmal activity has been detected which is time-locked to tics. Evoked responses are normal.

Reported data on almost $200 \mathrm{CT}$ scans has not revealed any consistent abnormality, with the majority of scans being normal. ${ }^{3}$ However, recent volumetric MRI studies in both children and adults with TS have shown that the left lenticular region is reduced in volume compared to control groups, resulting in loss of the usual asymmetry seen in the basal ganglia. ${ }^{16.17}$

Standard neuropsychological testing does not reveal any consistent abnormality. Some studies have shown Verbal IQ to be higher than Performance IQ, with specific abnormalities in drawing and remembering complex geometric figures, suggesting right frontotemporal dysfunction. ${ }^{18}$

\section{Genetics}

Detailed family studies ${ }^{9.19}$ have shown that in over $50 \%$ of families, TS is a hereditary disorder. The gene for TS most likely is inherited as an autosomal dominant trait, but penetrance is reduced, i.e., approximately $70 \%$ of individuals who have inherited the gene will develop symptoms. Tic severity is variable: some individuals in the family will have the full syndrome, others just chronic motor tics, or chronic vocal tics. Occasionally, some may exhibit only transient tics of childhood. ${ }^{20}$ In a recent study of 16 pairs of monozygotic twins, one of which had TS, the concordance for TS was $56 \%$. When any tic disorder was included, concordance rose to $94 \% .^{21}$

The trait is sex influenced, with males being more frequently affected than females. Obsessive - compulsive disorder may represent a manifestation of the TS gene, particularly in women. It has also been suggested that ADD may be an isolated manifestation of the TS gene,,$^{10}$ although this has been disputed in other studies..$^{9.15}$

With the identification of large families with TS, linkage studies are underway in several centers in an attempt to find the gene.

\section{Prevalence}

TS is found in all ethnic and racial groups although the exact prevalence is unknown due to misdiagnosis, under reporting, and few large epidemiological studies. Bruun 22 estimated a rate of 5 per 10,000 patients in the United States with males being affected approximately 3 times more often than females. A recent comprehensive study collected data from 142,636 pupils enrolled in schools in Monroe County, New York. ${ }^{23}$ Forty-one cases of TS were found for an estimated prevalence of 3 per 10,000 . Males were affected 9 times more often than females.

Although TS is uncommon, the gene for TS appears to be much more prevalent. When one considers that milder cases of TS remain undiagnosed, chronic motor or vocal tic disorder, and perhaps OCD are manifestations of the TS gene, the actual gene prevalence is estimated at 1 in 1,000 or higher. ${ }^{1,2}$

\section{Natural History}

TS is a lifelong illness. Although complete remission occasionally occurs in adulthood, most TS patients will continue to experience tics throughout their lives. Few longitudinal studies 
have been done, but it is generally felt that symptoms are most severe during adolescence, and improve in adulthood. Goetz et al ${ }^{24}$ in a retrospective study of 58 adult patients showed that $60 \%$ were considered to have moderate to severe tics in childhood, while only $24 \%$ had tics of this severity in adulthood. Twenty-two percent exhibited coprolalia as children, but only $4 \%$ as adults. The most significant predictor of tic severity in adulthood was tic severity in adolescence. The authors comment that the majority of individuals were able to lead reasonably normal lives, as $98 \%$ had completed high school, and $90 \%$ were employed.

\section{Differential Diagnosis}

Tansient tics in childhood have been reported to occur in up to $2.6 \%$ of children ${ }^{1}$ and represent a benign condition. The relationship of this disorder to TS is unclear, and it is important not to make a diagnosis of TS when tics have been present for less than one year.

Tics may result from a variety of insults to the brain, neurodegenerative conditions, and genetic disorders (Table 1). Encephalitis lethargica, HIV infections of the CNS, postencephalitic syndromes, and perinatal brain damage can result in tics. ${ }^{25}$ Tardive "Tourette syndrome" has occurred following use of neuroleptics. ${ }^{26}$ Isolated cases of tics have been reported following head trauma, ${ }^{27}$ carbon monoxide poisoning ${ }^{28}$ and withdrawal of chronic opiate therapy. ${ }^{29}$ Chromosomal disorders such as XXY, XYY, and fragile $\mathrm{X}$ syndrome should also be considered. ${ }^{30}$

Table 1. Differential Diagnosis of Tics and Tourette Syndrome.

1. transient tics of childhood

2. pre-natal/perinatal insults -congenital CNS defects

-birth defects

3. infections

-post-viral encephalitis

-HIV infections of CNS

4. head trauma

5. toxin exposure

-carbon monoxide

-gasoline

6. drugs

-neuroleptics ("tardive tics")

-levo-dopa

-opiate withdrawal

-amphetamines

7. chromosomal abnormalities

$-X Y Y$

$-X X Y$

-fragile $X$ syndrome

8. genetic disorders

-Hallervorden - Spatz disease

-Wilson's disease

-hyperekplexias

-Rett syndrome

-neuroaconthocytosis
Other conditions producing hyperkinesia such as athetoid cerebral palsy, dystonia musculorum deformans, Sydenham's chorea, Wilson's disease, Hallervorden-Spatz disease and juvenile Huntington's disease, should be considered in the differential diagnosis, but can be differentiated from TS by the neurological examination and appropriate investigations. Myoclonus may resemble tics, but is usually stimulus-sensitive, very rapid, and non-suppressible.

Hyperekplexia, also known as "jumping Frenchmen of Maine" ${ }^{31}$ or myriachit, refers to an unusual hereditary disorder characterized by an excessive startle reaction. Some patients may have echolalia and echopraxia, but true tics do not occur. It is still unclear whether hyperekplexia is psychogenic in nature or a true movement disorder.

\section{Etiology and Pathogenesis}

The underlying neurobiological mechanism for tics is unknown as routine post-mortem and biochemical studies are negative, and no adequate animal model exists. The two major hypotheses are that TS is the result of: 1) an abnormality in the dopaminergic system or 2) an abnormality in the endogenous opioid system.

Evidence that TS may be due to dopaminergic receptor hypersensitivity resides in observations that patients often improve with neuroleptic therapy, and tardive tics may result from chronic use. ${ }^{26}$ Reduced levels of homovanillic acid have been identified in the CSF of several patients. ${ }^{32}$ Postmortem analysis has shown an increased number of dopamine uptake carrier sites in the striatum in one study. ${ }^{33}$ However, PET studies reveal normal striatal dopaminergic and D2 receptor function. ${ }^{34}$

Recently, it has been reported that withdrawal of opiate therapy may result in an increase in tics, ${ }^{35}$ and use of these drugs may result in improvement, particularly of self injurious behaviour. ${ }^{29}$ Haber has reported post-mortem results on five patients with TS, showing decreased staining for dynorphin in the globus pallidus with normal staining for enkephalin. ${ }^{36}$

Based on abnormalities found in cases of acquired tic disorders, the anatomic localization of tics and associated behaviours has been suggested to be in the limbic forebrain structures and midbrain tegmentum. ${ }^{25.37}$ PET scanning in untreated TS patients using F18 - deoxyglucose shows decreased activity in the orbitofrontal cortex, inferior orbital cortex, mesial temporal cortex and striatum, and an abnormal functional relationship between the striatum and cortex. ${ }^{38}$ Recent MRI studies confirm that the basal ganglia play an important role..$^{6.17}$

TS may reflect an interaction between genetic and environmental factors, which would explain the variation in symptom severity. Hyde et al. ${ }^{21}$ found that in twins, the more severe symptoms were found in the twin with the lower birth weight.

\section{THERAPY}

Foremost in the treatment of TS is education of the patient and family. An explanation of the symptoms, including tics, obsessions, and compulsions allows for an appreciation that these are not voluntary or psychiatric behaviours. Frequently, the individual will suppress the tics throughout most of the day, only to exhibit many tics when he/she returns home from school or work. The family needs to understand that it is necessary for 
the person to "release" the tics. Particular times of the year may be more stressful than others, i.e., starting school, and will lead to an increase in tics. Education of teachers, (or co-workers in adulthood) is also important. Ongoing psychological counseling may be necessary to provide support for both the affected individual and family. Individuals with mild TS usually do not require medical therapy. When more sever symptoms are present, therapy should be individualized to treat the most distressing symptom(s).

Traditionally, neuroleptics have been used to control tics. Haloperidol has been used successfully as early as 1961, and still is commonly prescribed today. ${ }^{22}$ It should be started at a low dose at bedtime to prevent sedation, and increased very gradually. In many patients, $3-6 \mathrm{mg}$ is adequate to control symptoms. Side effects are common including sedation, Parkinsonism, cognitive impairment, and dysphoria. Acute dystonic reactions and akathisia may require the addition of an anticholinergic agent.

Pimozide has been shown to be effective in doses ranging 3 - 48 mg. ${ }^{39}$ In this study, patients experienced significantly fewer side effects on pimozide as compared to haloperidol, in particular related to sedation and lethargy. One potentially serious side effect of high dose pimozide therapy is prolongation of the $\mathrm{Q}$ - T interval: regular ECG monitoring is recommended at doses of $20 \mathrm{mg}$ per day or higher. ${ }^{40}$ Other neuroleptics probably are as effective as haloperidol or pimozide, and several may need to be tried in a patient to provide adequate tic benefit with minimal side effects. Some patients may develop a "tolerance" to one neuroleptic after several years treatment and need to be changed to another.

Although tardive dyskinesia occurs less frequently in TS than in other disorders, ${ }^{\prime}$ it remains a significant complication, particularly if treatment needs to be continued for many years. Tetrabenazine, a presymptomatic dopamine depleting agent, does not result in tardive dyskinesia and should be considered prior to neuroleptics particularly in less severe cases. Adequate tic control can usually be achieved at doses of 50 - $150 \mathrm{mg}$ per day. ${ }^{41}$ Common side effects include drowsiness, depression and weight gain. Although not available by prescription, it can be obtained through most Movement Disorders Clinics in Canada.

Recently, flunarizine, ${ }^{42}$ naloxone ${ }^{43}$ and opiates ${ }^{29.33}$ have been reported to be beneficial in controlling tics. Occasionally, a short course of benzodiazepines is required if the tics become severe in a stressful situation, and/or cause self-mutilatory behaviour.

All of the above medications should be used for as short a time as possible. Although long-term use may be necessary in more severe patients, many individuals will improve after several months or years of therapy, and the medication can slowly be tapered.

Treatment of ADD requires the use of stimulants, such as methylphenidate, even though they may unmask or exacerbate tics in up to $30 \%$ of children. ${ }^{44}$ Cautious trials are worthwhile as no change in tic severity is observed in the majority, and improvement in both behaviour and tics can occasionally be seen. Clonidine, an alpha2-adrenergic agonist, may be superior to stimulants, as it is effective in controlling $\mathrm{ADD}$, and may also be helpful in controlling tics, and OCD. ${ }^{45.46}$

For obsessive-compulsive symptomatology, anti-depressants such as clomipramine ${ }^{47}$ and fluoxetine ${ }^{48}$ have been shown to be useful. Neither drug has a beneficial or detrimental effect on tics.

\section{Conclusion}

Gilles de la Tourette syndrome, previously, thought to be a rare disorder, appears to be a relatively common condition with a variety of manifestations including chronic tic disorder and obsessive compulsive behaviour. In many individuals, symptoms are mild and may not require medical intervention, other than education and counseling. In more severely affected patients, symptoms usually can be adequately controlled by individualizing the treatment regime.

Genetic studies have led to a better understanding of this syndrome, although the association between TS, OCD, and ADD is still incompletely understood. Linkage analysis with isolation of the genetic defect should lead to the definition of the underlying biochemical abnormality.

\section{REFERENCES}

1. Shapiro AK, Shapiro ES, Young JG, Feinberg TE. Gilles de la Tourette syndrome. 2nd Edition, Raven Press, 1988.

2. Kurlan R. Tourette's syndrome: current concepts. Neurology 1989; 39: $1625-1630$.

3. Robertson MM. The Gilles de la Tourette syndrome: the current status. Br J Psychiatry 1989; 154: 147-169.

4. Comings DE, Comings BG. Tourette syndrome: clinical and psychological aspects of 250 cases. Am J Hum Genet 1985; 37: 435-450.

5. Erenberg G, Cruse RP, Roghner AD. Tourette syndrome an analysis of 200 pediatric and adolescent cases. Cleveland Clinic Quart 1986; 53: 127-131.

6. Comings DE, Comings BG. A controlled study of Tourette syndrome. IV Obsessions, compulsions and schizoid behaviours. Am J Hum Genet 1987; 41: 782-803.

7. Pitman RK, Green RC, Jenike MA, Mesulam MM. Clinical comparison of Tourette disorder and obsessive compulsive disorder. Am J Psychiatry 1987; 144: 1166-1171.

8. Leonard HLL, Lenane MC, Swedo, et al. Tics and Tourette's disorders: a 2 to 7 year follow-up of 54 obsessive-compulsive children. Am J Psychiatry 1992; 149: 1244-1251.

9. Pauls DL, Lechman JF. The inheritance of Gilles de la Tourette's syndrome and associated behaviours: evidence for autosomal dominant transmission. N Engl Med 1986; 315: 993-997.

10. Comings DE, Comings BG. A controlled study of Tourette syndrome. I. Attention-deficit disorder, learning disorders and school problems. Am J Hum Genet 1987; 41: $701-741$.

11. Comings DE, Comings BG. A controlled study of Tourette syndrome. VI Early development, sleep problems, allergies and handedness. Am J Hum Genet 1987; 41: 822-838.

12. Comings DE, Comings BG. A controlled study of Tourette syndrome. III Phobias and panic attacks. Am J Hum Genet 1987; 41: 761-781.

13. Comings DE, Comings BG. A controlled study of Tourette syndrome. V Depression and mania. Am J Hum Genet 1987; 41 : 804-821.

14. Comings DE, Comings BG. A controlled study of Tourette syndrome. II Conduct Am J Hum Genet 1987; 41: 742-760.

15. Pauls DL, Cohen DJ, Kidd KK, Lechman JF. Tourette syndrome and neuropsychiatric disorders: is there a relationship? Am J Hum Genet 1988; 42: 206-209.

16. Singer HS, Reiss AL, Brown JE, et al. Volumetric MRI changes in basal ganglia of Children with Tourette's syndrome. Neurology 1993; 43: 950-956.

17. Peterson B, Riddle MA, Cohen DR, et al. Reduced basal ganglia volumes in Tourette's syndrome using three-demensional reconstruction techniques from magnetic resonance images. Neurology 1993; 43: 941-949.

18. Sutherland RJ, Kolb W, Schoel WM, et al. Neuropsychological assessment of children and adults with Tourette syndrome: a comparison of learning disabilities and schizophrenia. Adv Neurol 1982; 35: 311-322. 
19. Pauls DL, Cohen DJ, Heimburch R, et al. Familial pattern and transmission of Gilles de la Tourette syndrome and multiple tics. Arch Gen Psychiatr 1981; 38: 1091-1093.

20. Kurlan R, Behr J, Medved L, Como P. Transient tic disorder and the clinical spectrum of Tourette's syndrome. Arch Neurol 1988; 45: 1200-1201.

21. Hyde TM, Aaronson BA, Randolph C, et al. Relationship of birth weight to the phenotypic expression of Gilles de la Tourette syndrome in monozygotic twins. Neurology 1992; 42: 652-658.

22. Bruun RD. Gilles de la Tourette's syndrome: an overview of clinical experience. J Am Acad Child Psychiatr 1984; 23: 126-133.

23. Caine ED, McBride MC, Chiverton P, et al. Tourette syndrome in Monroe County school children. Neurology 1988; 38: 472-475.

24. Goetz CG, Tanner CM, Stebbins GT, et al. Adult tics in Gilles de la Tourette syndrome: description and risk factors. Neurology 1992; 42: 784-788.

25. Northam RS, Singer HS. Postencephalitic acquired Tourette-like syndrome in a child. Neurology 1991; 41: 592-593.

26. Klawans HL, Falk DK, Nausiedo PA, Weiner WJ. Gilles de la Tourette's syndrome afer long term chlorpromazine therapy. Neurology 1978; 28: 1064-1068.

27. Fahn S. A case of post-traumatic tic syndrome. Adv Neurol 1982; 35: 349-350.

28. Pulst SM, Walshe TM, Romeo JA. Carbon monoxide poisoning with features of Gilles de la Tourette Syndrome. Arch Neurol 1983; 40: 443-445.

29. Bruun R, Kurlan R. Opiate therapy and self-harming behaviour in Tourette's syndrome. Mov Disord 1991; 6: 184-185.

30. Kerbeshian J, Burd L, Martsolf JT. Fragile X syndrome associated with Tourette symptomatology in a male with moderate mental retardation and autism. Dev Behav Pediatr 1984; 5; 201-203.

31. Saint-Hilaire MH, Saint-Hilaire JM, Granger L. Jumping Frenchmen of Maine. Neurology 1986; 36: 1269-1271.

32. Singer HS, Butler IJ, Tune LE et al. Dopaminergic dysfunction in Tourette syndrome. Ann Neurol 1982; 12:361-366.

33. Singer HS. Neurochemical analysis of post-mortem cortical and striatal brain tissue in patients with Tourette's syndrome. Adv Neurol 1992; 58; 135-144.

34. Brook DJ, Turjanski N, Sawle GV. PET studies on integrity of the pre- and post-synaptic dopaminergic system in Tourette's Syndrome. Adv Neurol 1991; 58: 227-231.
35. Lichter D, Majumdat L, Kurlan R. Opiate withdrawal unmasks Tourette's syndrome. Clin Neuropharmacol 1988; 11: 559-564.

36. Haber SN, Wolfer D. Basal ganglia peptidergic staining in Tourette syndrome. A follow-up study. Adv Neurol 1992; 58: 145-150.

37. Bonnet KA. Neurobiological dissection of Tourette syndrome: a neurochemical focus on a human neuroanantomical model. Adv Neurol 1982; 35: 77-82.

38. Stoetter B, Braun AR, Randolph C, et al. Functional neuroanatomy of Tourettes: limbic motor interactions studied with FDG PET. Adv Neurol 1992; 58: 213-256.

39. Shapiro AK, Shapiro E, Eisenbraft GJ. Treatment of Gilles de la Tourette syndrome with pimozide. Am J Psychiatry 1983; 140: 1183-1186.

40. Fulop G, Phillips RA, Shapiro AK, et al. ECG changes during haloperidol and pimozide treatment of Tourette's disorder. Am J Psychiatry 1987; 144: 673-675.

41. Jankovic J, Glaze DG, Frost JD. Effect of tetrabenazine on tics and sleep of Gilles de la Tourette's syndrome. Neurology 1984; 34: 688-692.

42. Micheli F, Gatto M, Lekhuniec E, et al. Treatment of Tourette syndrome with calcium antagonists. Clin Neurophamacol 1990; 13 77-83.

43. Sandyk R. The effects of naloxone in Tourette's syndrome. Ann Neurol 1985; 18: 367-368.

44. Erenberg G, Cruse RP, Rothner AD. Gilles de la Tourette's syndrome: effects of stimulant drugs. Neurology 1985; 35: 13461348.

45. Leckman JF, Cohen DJ, Deltor J, et al. Clonidine in the treatment of Tourette's syndrome: a review of data. Adv Neurol 1982; 35 : 391-401.

46. Hunt RD, Minderaa RB, Cohen DJ. Clonidine benefits children with attention deficit disorder and hyperactivity: report of a double-blind placebo-crossover therapeutic trial. J Am Acad Child Psychiatr 1989; 24: 583-586.

47. Cohen DJ, Riddle MA, Leckman JF. Pharmacotherapy of Tourette's syndrome and associated disorders. Psychiatr Clin North Am 1992; 15: 109-129.

48. Como PG, Kurlan R. An open label trial of fluoxetine for obsessive-compulsive disorder in Gilles de la Tourette's syndrome. Neurology 1991; 41: 872-847. 